\title{
In-vitroRelease of Rapamycin from a Thermosensitive Polymer for the Inhibition of Vascular Smooth Muscle Cell Proliferation
}

\author{
Weiwei Zhu ${ }^{a}$, Takahisa Masaki ${ }^{b}$, Alfred K. Cheung ${ }^{c, b}$, Steven E. Kern ${ }^{a, *}$ \\ aDepartment of Pharmaceutics and Pharmaceutical Chemistry, \\ University of Utah, Salt Lake City, UT 84108, USA \\ ${ }^{b}$ Department of Medicine, University of Utah, Salt Lake City, UT 84112, USA \\ 'Veterans Affairs Salt Lake City Healthcare System, UT 84148, USA \\ *Corresponding author: Steven E. Kern, Department of Pharmaceutics and \\ Pharmaceutical Chemistry, University of Utah, Salt Lake City, UT 84108, \\ USA, Tel: +1-801-585-5958; fax: +1-801-581-3674; E-mail address: Steven.Kern@utah.edu
}

Received March 31, 2009; Accepted May 05, 2009; Published May 06, 2009

Citation: Zhu W, Masaki T , Cheung AK, Kern SE (2009) In-vitro Release of Rapamycin from a Thermosensitive Polymer for the Inhibition of Vascular Smooth Muscle Cell Proliferation. J Bioequiv Availab 1: 003-012. doi:10.4172/jbb.1000002

Copyright: (C) $2009 \mathrm{Zhu} \mathrm{W}$, et al. This is an open-access article distributed under the terms of the Creative Commons Attribution License, which permits unrestricted use, distribution, and reproduction in any medium, provided the original author and source are credited.

\begin{abstract}
Hemodialysis arteriovenous grafts are often plagued by stenosis at the anastomosis, which is due to the proliferation of vascular smooth muscle cells (SMCs). To prevent the stenosis, we have been developing a strategy for the sustained perivascular delivery of an antiproliferative agent, rapamycin, using an injectable biodegradable polymer, ReGel $^{\circledR}$. In this study we examined the in-vitro kinetics of rapamycin released from ReGel and its efficacy for inhibiting the proliferation of human and porcine venous and arterial SMCs. To study the release from ReGel, rapamycin was mixed with ReGel and incubated at $37^{\circ} \mathrm{C}$ in a release medium. The release medium was periodically sampled and assayed for rapamycin concentration by UV. Cellular uptake and release of rapamycin were examined by incubating SMCs with rapamycin for various durations. Intracellular drug was extracted and measured by HPLC. Antiproliferative effects and cytotoxicity of stock rapamycin and that released from ReGel were examined using cell counting and lactate dehydrogenase (LDH)-release assay, respectively. Rapamycin exhibited a sustained-release pattern from ReGel for 52 days. The kinetics of rapamycin transport through the cell membrane was compatible with a passive diffusion mechanism. Rapamycin released from ReGel exhibited antiproliferative activity similar to the free drug. Our results support the concept of sustained delivery of rapamycin using ReGel as a promising strategy to inhibit SMC proliferation for the prevention of hemodialysis arteriovenous graft stenosis.
\end{abstract}

\section{Introduction}

The arteriovenous polytetrafluoroethylene (PTFE) graft has served as a predominant form of vascular access for chronic hemodialysis in the United States. Unfortunately, graft failure occurs frequently, with most cases due to stenosis at the anastomosis followed by thrombosis. The pathology of the stenosis is usually neointimal hyperplasia, which primarily results from the proliferation and migration of vascular smooth muscle cells (SMCs) (Swedberg et al., 1989). In recent years, the porcine arteriovenous graft model has been increasingly used for the investigation of the pathogenesis of the stenosis (Johnson et al., 2001; Kelly et al., 2002; Rotmans et al., 2003). This model has demonstrated that the neointima forms early, within 2-3 weeks following graft placement. In dialysis patients, hemodynamically significant stenosis appears to develop progressively, partly attributed to the chronic turbulent blood flow and compliance mismatch between the graft and native vessels. Thus the continuous inhibition of SMC proliferation using antiproliferative agents can be a logical strategy to prevent the stenosis.

Rapamycin is a drug with potent inhibitory activities on the proliferation and migration of human and rat aortic SMCs in-vitro (Marx et al., 1995; Poon et al., 1996). Its 
antiproliferative activity is believed to be mediated by its binding to a 12-kDa intracellular molecule, the FK506 binding protein (FKBP12) (Bierer et al., 1990). The rapamycinFKBP complex inhibits the activity of a kinase known as mammalian target of rapamycin (mTOR), resulting in an increased level of cyclin-dependent kinase inhibitors (CDKI) with the subsequent cell cycle arrest in $\mathrm{G}_{1} / \mathrm{S}$ transition (Gallo et al., 1999).

Our group has been investigating perivascular drug delivery using a biodegradable polymer, $\operatorname{ReGel}^{\circledR}$, which provides a platform for sustained release of the drug from the adventitial side of the graft-vessel anastomosis (Kuji et al., 2006; Masaki et al., 2004; Zentner et al., 2001; Zhu et al., 2006). ReGel is thermosensitive which allows for easy mixing with rapamycin and also easy injection into the physiologic site of interest. This enables the drug depot to be replenished if necessary which may be crucial to this application since the graft is continually subjected to stimuli which would encourage SMC proliferation.

As an initial step in this strategy, we examined the invitro release kinetics of rapamycin from ReGel, the transport properties of the drug in SMCs, and the pharmacodynamics of the drug after release from ReGel. In preparation for testing in the porcine model and clinical trials, these experiments were performed in both human and porcine SMCs. In addition, since stenosis develops in both venous and arterial anastomoses of the hemodialysis graft with increasing evidence that venous and arterial SMCs may respond differently to various antiproliferative drugs, both venous and arterial SMCs were examined (Kim et al., 2004; White et al., 2000; Yang et al., 1998). The ultimate objective is to investigate the potential of this combination of delivery system and drug for the prevention of vascular smooth muscle cell proliferation, a primary cause of hemodialysis arteriovenous graft stenosis.

\section{Materials and Methods}

All animal experiments were conducted with approval from the IACUC of the University of Utah and the Salt Lake Veterans Administration Research Center.

\section{Materials}

Rapamycin was purchased from LC Laboratories (Woburn, MA). ReGel ${ }^{\circledR}$ was obtained from MacroMed Inc (Sandy, UT). Two individual cell lines of human saphenous venous and aortic SMCs, and smooth muscle growth medium-2 bullet kit were purchased from Clonetics (Walkersville, MD). The smooth muscle growth medium was supplemented with $10 \%$ fetal calf serum, $5 \mu \mathrm{g} / \mathrm{ml}$ insulin, $0.5 \mathrm{ng} / \mathrm{ml}$ human recombinant epidermal growth factor
(EGF), $2 \mathrm{ng} / \mathrm{ml}$ human recombinant fibroblast growth factor (FGF), $50 \mu \mathrm{g} / \mathrm{ml}$ gentamicin and $50 \mathrm{ng} / \mathrm{ml}$ amphotericin-B. Fluorescein isothiocyanate (FITC)-conjugated antihuman smooth muscle actin and lactate dehydrogenase (LDH) assay kits (substrate, cofactor, dye and lysis solution) were purchased from Sigma-Aldrich (St Louis, MO).

\section{In-vitro Release of Rapamycin from ReGel}

Rapamycin was mixed with $0.4 \mathrm{ml}$ of $\mathrm{ReGel}$ at $4{ }^{\circ} \mathrm{C}$ to form a $10 \mathrm{mg} / \mathrm{ml}$ liquid mixture in a $20-\mathrm{ml}$ vial. It was then maintained at $37^{\circ} \mathrm{C}$ to form a gel in the bottom of the vial. Release medium (15 mL) made from PBS-ethanol (90:10 $\mathrm{v} / \mathrm{v}, \mathrm{pH}$ 7.6) (Alexis et al., 2004) was added to the vial. The vial was incubated in a $37^{\circ} \mathrm{C}$ water bath with agitation at 50 $\mathrm{rpm}$. Medium was sampled daily from the vial and replaced with fresh medium. Rapamycin concentration was measured in the sampled medium by UV spectrometry (Ultrospec III, Pharmacia LKB, McAllen, TX) at $277 \mathrm{~nm}$, using standards of $0-20 \mu \mathrm{g} / \mathrm{ml}$.

To assess whether rapamycin released from ReGel altered its anti-proliferative activity, rapamycin $(10 \mathrm{mg} / \mathrm{ml}$ in $0.4 \mathrm{ml}$ of ReGel) or ReGel alone $(0.4 \mathrm{ml})$ was incubated in $15 \mathrm{ml}$ of culture medium at $37^{\circ} \mathrm{C}$ for $24 \mathrm{hrs}$. The medium was assayed for rapamycin concentration and $\mathrm{pH}$, and then diluted to $0.1,10$ and $100 \mathrm{ng} / \mathrm{ml}$. These solutions of rapamycin were then used in cell culture experiments as described below.

\section{Cell Culture}

Porcine venous and arterial SMCs were isolated from the normal femoral veins and arteries of two Yorkshire cross domestic pigs and cultured. Briefly, the femoral veins or arteries (5-cm length) were minced into pieces of approximately $1 \mathrm{~mm}^{3}$ in size. Endothelial cells were detached from the segments by incubating with collagenase A $(5 \mathrm{mg} / \mathrm{ml})$ at $37^{\circ} \mathrm{C}$ for $10 \mathrm{~min}$. The remaining SMCs were cultured in the culture medium at $37^{\circ} \mathrm{C}$ in a humidified $5 \% \mathrm{CO}_{2}$ incubator. SMCs were identified by their typical elongated swirling and overlapping morphology under the light microscope and positive staining with FITC-conjugated anti-smooth muscle actin. Human venous and arterial SMCs were also grown in the culture medium at $37^{\circ} \mathrm{C}$ in a humidified $5 \%$ $\mathrm{CO}_{2}$ incubator. Cells from passage 3-5 were used in experiments as described below.

\section{Cellular Uptake and Release of Rapamycin}

Human venous SMCs were seeded at a density of $1 \times 10^{5}$ cells per well in a 12-well plate and cultured for $24 \mathrm{hrs}$. Rapamycin was dissolved in ethanol and diluted in culture medium to a final ethanol concentration of $0.5 \%(\mathrm{v} / \mathrm{v})$. For uptake measurement, cells were incubated with 5,15 or 25 
$\mu \mathrm{g} / \mathrm{ml}$ of rapamycin at $37^{\circ} \mathrm{C}$ for incremental durations. For release measurement, cells were incubated with 5,15 or 25 $\mu \mathrm{g} / \mathrm{ml}$ of rapamycin at $37^{\circ} \mathrm{C}$ for $2 \mathrm{hrs}$ and further incubated in a fresh drug-free medium for incremental durations. At the end of incubation, the cells were washed with PBS, and the intracellular rapamycin was extracted with a Triton X100 solution (the lysis buffer from a LDH assay kit). After centrifugation (TJ-6, Beckman Coulter, Fullerton, CA) at $3000 \mathrm{rpm}$ for $5 \mathrm{~min}, 50 \mu \mathrm{l}$ of the supernatant was subjected to HPLC analysis.

High pressure liquid chromatography (HPLC) was performed using a Waters HPLC system (Waters Corporation, Milford, MA) consisting of dual pumps, an autosampler and a photodiode array detector. $\mathrm{AC}_{18}$ analytic column (150 $\mathrm{mm} \times 4.6 \mathrm{~mm}, 3 \mu \mathrm{m}, 100$ ?, Ascentis ${ }^{\circledR}$ column, SigmaAldrich, St Louis, $\mathrm{MO}$ ) was used preceded by a $\mathrm{C}_{18}$ guard column $\left(2 \mathrm{~cm} \times 4.0 \mathrm{~mm}, 5 \mu \mathrm{m}, 100\right.$ ?, Ascentis ${ }^{\circledR}$ Supelguard $^{\circledR}$ cartridge, Sigma-Aldrich, St Louis, MO). The mobile phase containing a mixture of $42 \%$ acetonitrile, $30 \%$ methanol and $28 \%$ water, was filtered and degassed. HPLC was carried out at the flow rate of $1 \mathrm{ml} / \mathrm{min}$, with the analytic column temperature set at $45^{\circ} \mathrm{C}$, the UV detection at $270-290$ $\mathrm{nm}$, and the running time per sample of $30 \mathrm{~min}$. Rapamycin concentration was calculated by the peak height. Rapamycin concentrations of $10-10,000 \mathrm{ng} / \mathrm{ml}$ were used as standards. With the injection volume of $50 \mu 1$, the minimum detectable concentration of rapamycin was $10 \mathrm{ng} / \mathrm{ml}$. In addition to the drug extracted from the cells, the drug concentration in the remaining medium was also measured to determine the total amount in each experiment. Using the mass balance, the recovery rate of rapamycin from the cells was determined to be $96.9 \pm 3.8 \%$.

\section{Cell Proliferation Assay}

To examine if the incorporation of rapamycin into ReGel affects the pharmacological activity of the drug, rapamycin released from ReGel was tested for cell proliferation. Human and porcine venous and arterial SMCs were seeded at a density of $2.5 \times 10^{4}$ cells per well in a 12 -well plate and cultured for $24 \mathrm{hrs}$. The culture medium was replaced with a fresh medium containing various concentrations of rapamycin that had been released from ReGel as described above $(0.1,10$ and $100 \mathrm{ng} / \mathrm{ml})$ or from stock rapamycin $(0.001 \mathrm{ng} / \mathrm{ml}-1 \mathrm{mg} / \mathrm{ml})$. A vehicle of $0.5 \%(\mathrm{v} / \mathrm{v})$ ethanol in culture medium served as a control. The cells were cultured for $72 \mathrm{hrs}$ and the proliferation was assessed by cell counting using a hemocytometer after trypsin digestion.

\section{Cytotoxicity Assay}

Human and porcine venous and arterial SMCs were seeded at a density of $2.5 \times 10^{3}$ cells per well in a 96-well plate and cultured for $24 \mathrm{hrs}$. After incubation with various concentrations of free rapamycin $(0.001 \mathrm{ng} / \mathrm{ml}-1 \mathrm{mg} / \mathrm{ml})$ or rapamycin released from $\operatorname{ReGel}(0.1,10$ or $100 \mathrm{ng} / \mathrm{ml})$ for $72 \mathrm{hrs}$, the plate was centrifuged at $1000 \mathrm{rpm}$ for $4 \mathrm{~min}$. The supernatant containing the released lactate dehydrogenase (LDH) from the damaged cells was set aside. The cells remaining in the plate were lysed to release the intracellular LDH. The supernatant and the cell lysate were separately subjected to the LDH assay. In brief, $50 \mu 1$ of the mixture of LDH-assay substrate, cofactor and dye solution (1:1:1) was added to each well, and the plate was incubated at room temperature for $30 \mathrm{~min}$, followed by the addition of $15 \mu 1$ of $1 \mathrm{~N} \mathrm{HCl}$ to each well. The absorbance at $492 \mathrm{~nm}$ $\left(\mathrm{A}_{492}\right)$ was measured with the reference wavelength of 690 $\mathrm{nm}$. The percentage of LDH released from damaged cells was calculated as $\mathrm{A}_{492}$ of released $\mathrm{LDH} /\left(\mathrm{A}_{492}\right.$ of released $\mathrm{LDH}+\mathrm{A}_{492}$ of $\mathrm{LDH}$ from lysed cells $) \times 100$.

\section{Data Analysis}

Each experiment was performed 3-6 times on separate days. All values were expressed as mean \pm SD. Mean values were compared using one-way or two-way ANOVA with the Tukey test for multiple comparisons. P value less than 0.05 was considered significant.

The data on in-vitro drug release from ReGel were further analyzed. A mathematical model for drug release from a biodegradable matrix has been proposed with the following assumptions. (1) Drug release follows the mechanism of drug diffusion and polymer degradation that occur simultaneously. (2) The initial drug loading is well above the solubility of the drug within the matrix that mimics a pseudosteady state of drug diffusion. (3) Polymer matrix undergoes a homogeneous erosion process and the chain cleavage follows first-order kinetics. The following equation for the cumulative absolute amount of drug released, $Q$, versus time $t$ has been derived (Charlier, Leclerc, and Couarraze 2000):

$$
Q=S \sqrt{\frac{2 C_{0} C_{S} D_{0}\left(e^{k t}-1\right)}{k}}
$$

Where $S$ is surface area of the matrix exposed to the release medium; $C_{0}$ and $C_{\mathrm{s}}$ are initial drug concentration and drug solubility in the matrix, respectively; $D_{0}$ is drug diffusion coefficient at time 0 ; and $k$ is polymer degradation rate constant. At early time points ( $t$ near 0$), e^{k t} \approx 1+k t$, therefore

$$
Q=S \sqrt{2 C_{0} C_{s} D_{0} t}
$$


Thus, the product of $C_{\mathrm{s}}$ and $D_{0}$, could be an indicator of the released drug amount at early time points, given the constant values of $S$ and $C_{0}$. Rapamycin release data were fitted to Equation 1 using the nonlinear regression function in SigmaPlot (Systat Software, Point Richmond, CA) to determine $D_{0}$ and $k$. We have previously examined the invitro release kinetics of a relatively hydrophilic drug, dipyridamole, from ReGel or polymeric microspheres mixed with ReGel (Zhu et al., 2006). Dipyridamole release data were also analyzed for comparison with rapamycin.

The data on cellular uptake of rapamycin were further analyzed by calculating the uptake rate constant $k_{\mathrm{u}}$ and release rate constant $k_{\mathrm{r}}$. Assuming a two-compartment model for drug permeation between the extracellular medium (compartment 1) and the intracellular space (compartment 2), and the first-order kinetics of drug permeation, intracellular rapamycin concentration $C_{2}$ at time $t$ can be expressed as:

$$
V_{2} \frac{d C_{2}}{d t}=V_{1} C_{1} k_{u}-V_{2} C_{2} k_{r}
$$

Where $V_{1}$ and $V_{2}$ are volume of the extracellular medium and the intracellular space, respectively; and $C_{1}$ is rapamycin concentration in the extracellular medium, respectively. Let $C_{0}$ represent the drug concentration in the medium at the beginning of incubation. Substitution of $V_{1} C_{1}$ by $\left(V_{1} C_{0}-V_{2} C_{2}\right)$ gives:

$$
V_{2} \frac{d C_{2}}{d t}=\left(V_{1} C_{0}-V_{2} C_{2}\right) k_{u}-V_{2} C_{2} k_{r}
$$

By integration of Equation 4 when $C_{2}=0$ at time $0, C_{2}$ at time $t$ can be expressed as:

$$
C_{2}=\frac{V_{1} C_{0} k_{u}}{V_{2}\left(k_{u}+k_{r}\right)}\left(1-e^{-\left(k_{u}+k_{r}\right) t}\right)
$$

At 2 hours when cellular uptake of rapamycin reached equilibrium, intracellular drug concentration $C_{2, \mathrm{sS}}$ can be expressed as:

$$
C_{2, s s}=\frac{V_{1} C_{0} k_{u}}{V_{2}\left(k_{u}+k_{r}\right)}
$$

Therefore,

$$
\frac{C_{2}}{C_{2, s s}}=1-e^{-\left(k_{u}+k_{r}\right) t}
$$

Rapamycin cellular uptake data were fitted to Equation 7 for the calculation of $k_{\mathrm{u}}$ and $k_{\mathrm{r}}$ using the nonlinear regres-

\section{sion function in SigmaPlot.}

Temperature-dependent cellular uptake data were fitted to the following bi-exponential equation using the nonlinear regression function in SigmaPlot.

$$
M=a e^{b T}
$$

Where $M$ is the percentage of intracellular rapamycin amount at the steady state at temperature $T$ relative to that at $37^{\circ} \mathrm{C} ; a$ and $b$ are factors related to the membrane transport properties of rapamycin. The mechanism of drug transport through the lipid bilayer of the cell membrane can be reflected by the temperature coefficient $Q_{10}$, defined as the factor by which the intracellular drug concentration at the steady state $\left(C_{\mathrm{ss}}\right)$ increases as the temperature is raised by $10^{\circ} \mathrm{C}$. A larger $Q_{10}$ suggests a larger activation energy involved (Hille 1984; Stein 1967), which is related to the diffusion mechanism. Low temperature dependence with a low $Q_{10}$ value $(<2)$ is suggestive of a passive diffusion mechanism. High temperature dependence with a high $Q_{10}$ value $(>6)$ suggests a facilitated diffusion or active transport process. Moderate $Q_{10}$ between 2 to 6 cannot directly indicate the diffusion mechanism (Lane et al., 1987). $Q_{10}$ can be calculated as:

$$
Q_{10}=e^{10 b}
$$

The concentrations of rapamycin which produce $50 \%$ of the maximal antiproliferative effect $\left(E C_{50}\right)$ and induce $50 \%$ of the maximal lethal (toxic) effect $\left(L C_{50}\right)$ were obtained by fitting the respective concentration-effect data to the following sigmoid $E_{\max }$ equation (or Hill equation) using the nonlinear regression function in SigmaPlot.

$$
E=\frac{E_{\max } \cdot C^{n}}{E C_{50}^{n}+C^{n}}
$$

Where $E$ is the percentage of antiproliferative or toxic effect at concentration $C$ relative to the maximal antiproliferative or toxic effect $E_{\max }(100) ; E C_{50}$ is the concentration of drug that produces $50 \%$ of the maximal antiproliferative or toxic effect; $n$ is the shape factor. Therapeutic index is calculated as the ratio of $L C_{50}$ to $E C_{50}$.

\section{Results}

In the present study, we first examined the in-vitro release of rapamycin from ReGel. The release was gradual and sustained over 52 days (Fig. 1). We have previously examined the in-vitro release of dipyridamole from ReGel (Zhu et al., 2006). Approximately $40 \%$ of dipyridamole was released as an initial burst in the first 3 days, followed by a gradual release in the subsequent 2 weeks. 


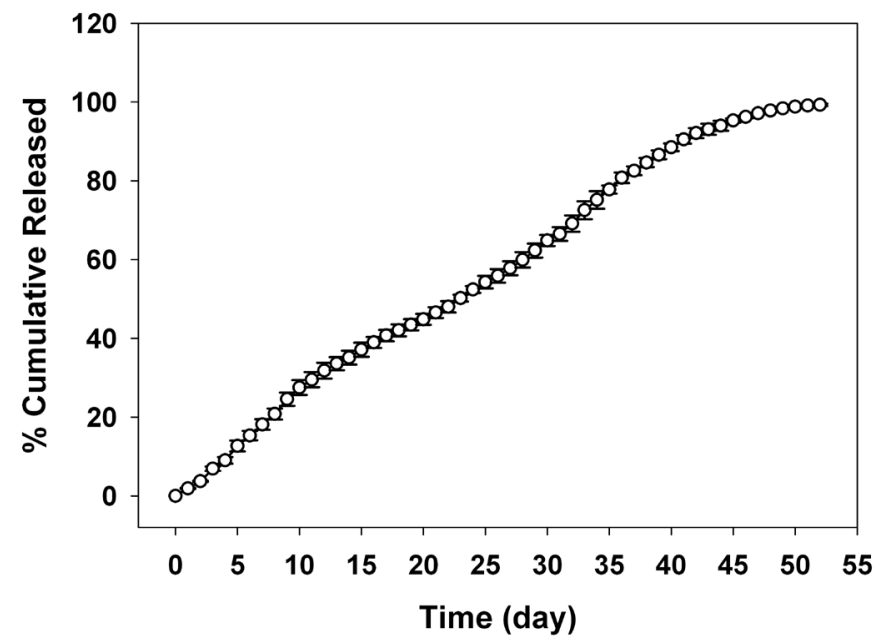

Figure 1: In-vitro release of rapamycin from ReGel. The release rate is relatively constant over 45 days with no significant initial burst release. Each data point represents the mean \pm SD of 3 experiments.

\begin{tabular}{|c|c|c|c|c|}
\hline & $D_{0}\left(\mathrm{~cm}^{2} / \mathrm{s}\right)$ & $D_{0} C_{\mathrm{s}}(\mathrm{g} / \mathrm{cm} \cdot \mathrm{s})$ & $k\left(\right.$ day $\left.^{-1}\right)$ & $R^{2}$ \\
\hline Rapamycin from ReGel & $3.89 \pm 0.24 \times 10^{-8}$ & $2.60 \pm 0.16 \times 10^{-12}$ & $3.95 \pm 0.24 \times 10^{-2}$ & 0.979 \\
\hline Dipyridamole from ReGel & $8.45 \pm 0.30 \times 10^{-8}$ & $1.64 \pm 0.06 \times 10^{-11}$ & $3.70 \pm 0.47 \times 10^{-2}$ & 0.963 \\
\hline Dipyridamole from microspheres mixed with ReGel & $1.96 \pm 0.32 \times 10^{-8}$ & $3.80 \pm 0.62 \times 10^{-12}$ & $1.06 \pm 0.12 \times 10^{-1}$ & 0.949 \\
\hline
\end{tabular}

$D_{0}$ : drug diffusion coefficient at time $0 ; C_{\mathrm{s}}$ : drug solubility in the polymer matrix; $k$ : polymer degradation rate constant.

Each value represents the mean \pm SD of 3 experiments.

Table 1: The in vitro drug release parameters of Dipyridamole and Rapamycin from ReGel and ReGel with microspheres.

The drug diffusion coefficient at $t=0, D_{0}$, and polymer degradation rate constant, $k$ (Table 1 ) was smaller for rapamycin $\left(3.89 \pm 0.24 \times 10^{-8} \mathrm{~cm}^{2} / \mathrm{s}\right)$ than dipyridamole $\left(8.45 \pm 0.30 \times 10^{-8} \mathrm{~cm}^{2} / \mathrm{s}\right)$. This may partly be attributed to the larger size of rapamycin (MW 914.2 vs. 504.6). It may also be a result of the difference in their hydrophobicity, since the higher hydrophobicity of rapamycin may retard the drug release from the hydrophilic domain of the polymer. The $C_{\mathrm{s}} D_{0}$ of rapamycin $\left(2.60 \pm 0.16 \times 10^{-12} \mathrm{~g} / \mathrm{cm} \cdot \mathrm{s}\right)$ is smaller than that of dipyridamole $\left(1.64 \pm 0.06 \times 10^{-11} \mathrm{~g} / \mathrm{cm} \cdot \mathrm{s}\right)$, indicating the slower release rate of rapamycin at early time. There was no significant difference in $k$ of ReGel when mixed with either drug. Incorporation of dipyridamole into microspheres decreased the $D_{0}\left(1.96 \pm 0.32 \times 10^{-8} \mathrm{~cm}^{2} / \mathrm{s}\right)$ and $C_{\mathrm{s}} D_{0}\left(3.80 \pm 0.62 \times 10^{-12} \mathrm{~g} / \mathrm{cm} \cdot \mathrm{s}\right)$, and increased the $k$.

The uptake and release of rapamycin in human venous SMCs were quantified by measuring cell-associated rapamycin at various time points (Fig. 2). Cellular uptake of rapamycin was rapid and reached a plateau in $30 \mathrm{~min}$. The concentrations chosen for the uptake experiments were below the $\mathrm{LC}_{50}$ but high enough to assure that they could be accurately assayed during the washout experiments. Cellular uptake and release rate constants $\left(\mathrm{k}_{\mathrm{u}}\right.$ and $\left.\mathrm{k}_{\mathrm{r}}\right)$ of rapamycin showed no significant differences among the three drug concentrations tested (Table 2), which is compatible with a passive diffusion mechanism for rapamycin transport through the cell membrane. The uptake of rapamycin reached a steady state in $30 \mathrm{~min}$ at $37^{\circ} \mathrm{C}$ and 60 min at $4^{\circ} \mathrm{C}$, which persisted for several hours thereafter when the extracellular drug was maintained in the medium. Therefore, the temperature-dependence study was performed using a constant incubation time of $2 \mathrm{hrs}$ to ensure the equilibrium of drug uptake. $\mathrm{Q}_{10}$, the temperature coefficient, was calculated to be below 2 over the range of concentration evaluated (Table 2) which is also consistent with a passive diffusion model of drug transport.

The proliferation of human and porcine venous SMCs was attenuated in a dose-dependent manner by treatment with rapamycin (Fig. 3A and 3B). Rapamycin $E C_{50}$ in human and porcine arterial SMCs were significantly (1.8 and 2.0 times, respectively; $\mathrm{P}<0.05$ ) higher than those in the corresponding venous SMCs (Table 3 ). The $E C_{50}$ in porcine venous and arterial SMCs were significantly (1.3 and 1.5 times, respectively; $p<0.05$ ) higher than those in the corresponding human SMCs. 


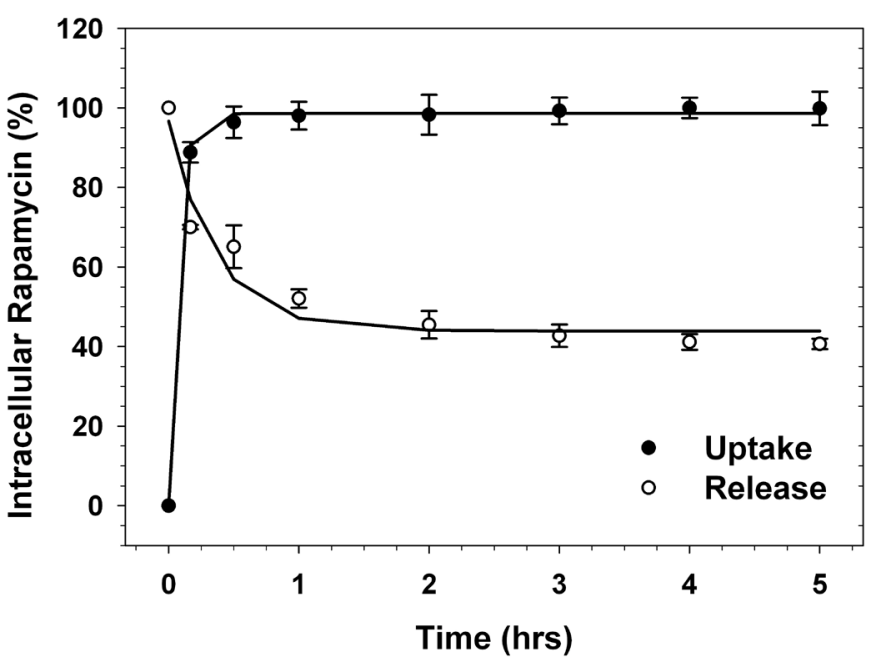

Figure 2: Uptake and release of rapamycin in human venous SMCs. The rate of uptake is faster than the rate of release. In addition, release is extended because rapamycin likely binds within the cell. Each data point represents the mean $\pm \mathrm{SD}$ of 3 experiments.

\begin{tabular}{|c|c|c|c|}
\hline $\begin{array}{c}C_{\text {initial }} \\
(\mu \mathrm{g} / \mathrm{ml})\end{array}$ & $k_{\mathrm{u}}\left(\mathrm{min}^{-1}\right)$ & $k_{\mathrm{r}}\left(\mathrm{min}^{-1}\right)$ & $Q_{10}$ \\
\hline 5 & $0.00073 \pm 0.00006$ & $0.0356 \pm 0.0046$ & $1.13 \pm 0.16$ \\
\hline 15 & $0.00072 \pm 0.0001$ & $0.0355 \pm 0.0024$ & $1.22 \pm 0.22$ \\
\hline 25 & $0.00070 \pm 0.00007$ & $0.0326 \pm 0.0049$ & $1.35 \pm 0.27$ \\
\hline
\end{tabular}

$C_{\text {initial }}:$ initial rapamycin concentration in the medium; $k_{\mathrm{u}}$ : uptake rate constant; $k_{\mathrm{r}}$, release rate constant; $Q_{10}$, the factor by which the cellular drug concentration at steady state increases as the temperature is raised by $10^{\circ} \mathrm{C}$. Each value represents the mean \pm SD of 3 experiments

Table 2: Pharmacokinetic parameters for uptake and release of rapamycin in human venous SMCs.

In assessing the cytotoxicity of rapamycin (Figure 3A and 3B), LDH release did not increase at rapamycin concentrations lower than $100 \mathrm{ng} / \mathrm{ml}$, indicating the antiproliferative effect of rapamycin was a pharmacologic and not a toxic effect. At concentrations higher than $1000 \mathrm{ng} / \mathrm{ml}$, however, LDH release was increased and significantly higher than the control $(\mathrm{P}<0.05)$, indicating that the anti-proliferative effect at these concentrations was partially due to toxicity. The rapamycin concentration which produced $50 \%$ of the maximal $\mathrm{LDH}$ release, $L C_{50}$, was significantly (1.4 and 1.5 times, respectively) higher in human and porcine venous than in the corresponding arterial cells $(\mathrm{P}<0.05)$, while it was not significantly different between porcine SMCs (venous or arterial) and the corresponding human cells (Table 3). Consequently, the therapeutic index $\left(L C_{50} / E C_{50}\right)$ was significantly (2.4 and 3.0 times, respectively; $\mathrm{P}<0.05$ ) higher in human and porcine venous SMCs than in the corresponding arterial SMCs, and significantly (1.3 and 1.6 times, respectively; $\mathrm{P}<0.05$ ) higher in human venous and arterial SMCs than in the corresponding porcine SMCs.

Comparing the effect or rapamycin released from ReGel versus rapamycin applied directly to the SMCs, there was no difference seen in between the two experimental conditions as shown in Figure 4. While this is an anticipated result - there is not an expectation that rapamycin released from the gel is altered in any significant way - this experiment does confirm that ReGel is not interacting with rapamycin in any way to alter the inhibition of cellular proliferation. Given that ReGel is composed of polymers that have been used for drug delivery applications in the past with no significant toxicity, this confirmation is for completeness.

(A)

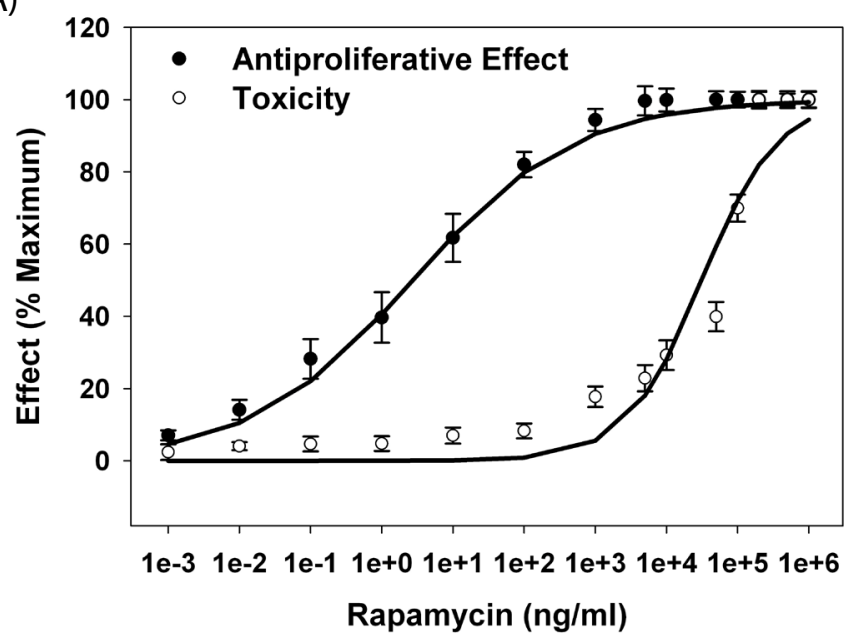

(B)

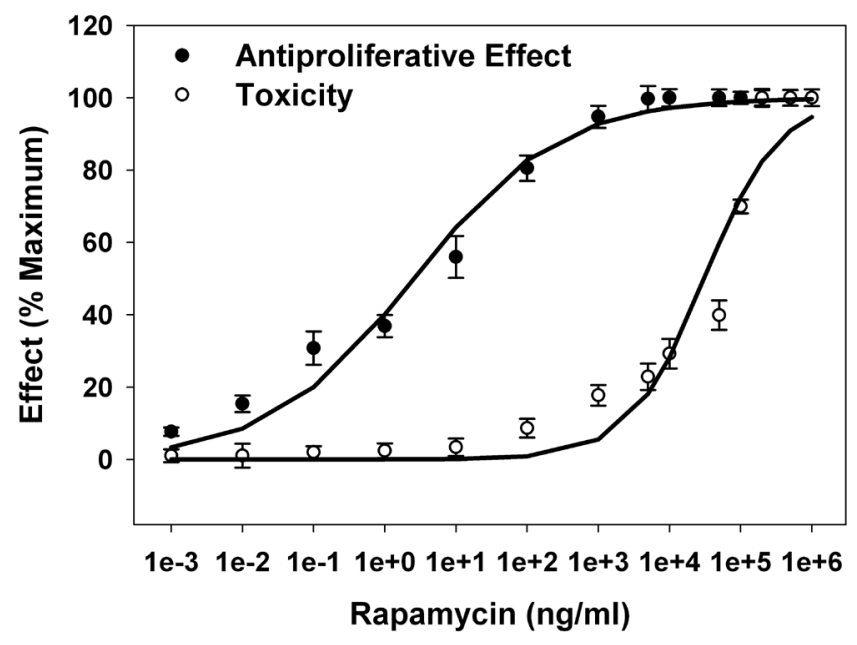

Figure 3: Antiproliferative effect and toxicity of rapamycin in (A) human venous SMCs and (B) porcine venous SMCs. The results show that the in-vitro efficacy and therapeutic index is not different between these two cell models. Each data point represents the mean $\pm \mathrm{SD}$ of 6 experiments. 


\begin{tabular}{|c|c|c|c|c|}
\hline Parameters & $\begin{array}{c}\text { Human venous } \\
\text { SMC }\end{array}$ & Human arterial SMC & $\begin{array}{c}\text { Porcine venous } \\
\text { SMC }\end{array}$ & $\begin{array}{c}\text { Porcine arterial } \\
\text { SMC }\end{array}$ \\
\hline$E C_{50}(\mathrm{ng} / \mathrm{ml})$ & $2.52 \pm 0.40$ & $4.45 \pm 0.59 *$ & $3.39 \pm 0.65$ & $6.70 \pm 0.85 *$ \\
\hline$L C_{50}(\mathrm{ng} / \mathrm{ml})$ & $(3.86 \pm 0.65) \times 10^{4}$ & $(2.80 \pm 0.37) \times 10^{4} *$ & $(3.85 \pm 0.63) \times 10^{4}$ & $(2.57 \pm 0.34) \times 10^{4} *$ \\
\hline Therapeutic index & $(1.53 \pm 0.21) \times 10^{4}$ & $(6.29 \pm 0.83) \times 10^{3} *$ & $(1.14 \pm 0.10) \times 10^{4}$ & $(3.85 \pm 0.51) \times 10^{3} *$ \\
\hline
\end{tabular}

$E C_{50}$, concentration of rapamycin that produces $50 \%$ of the maximal antiproliferative Effect; $L C_{50}$ : concentration of rapamycin that induces $50 \%$ of the maximal toxicity; therapeutic index, ratio of $L C_{50}$ to $E C_{50}$. Each value represents the mean $\pm \mathrm{SD}$ of 6 experiments. ${ }^{*} \mathrm{P}<0.05$ vs. corresponding value in venous SMCs of the same species.

Table 3: Pharmacodynamic parameters for antiproliferative effect and toxicity of rapamycin in human and porcine venous and arterial SMCs.

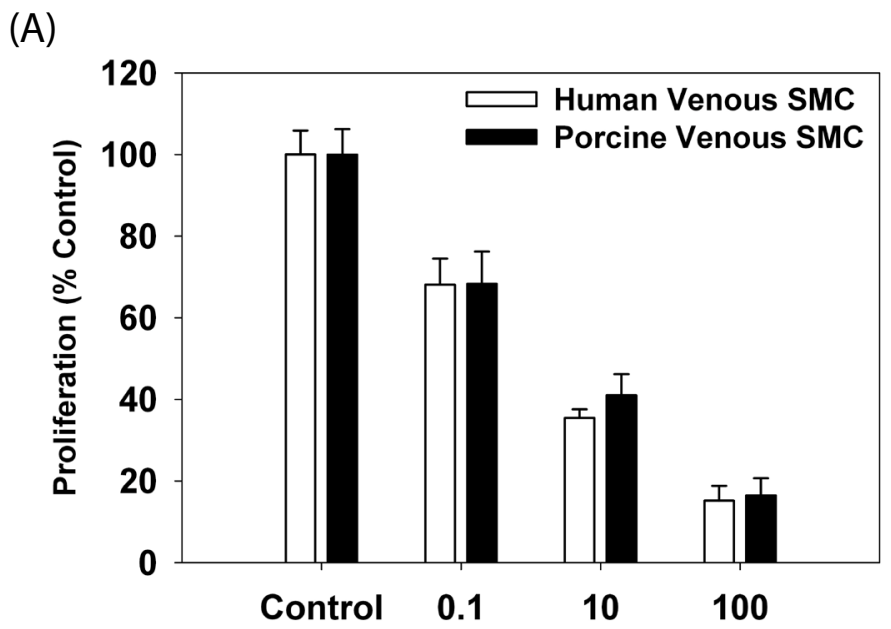

(B)

Rapamycin released from $\mathrm{ReGel}(\mathrm{ng} / \mathrm{ml})$

\section{Rapamycin Effect on SMC Proliferation}

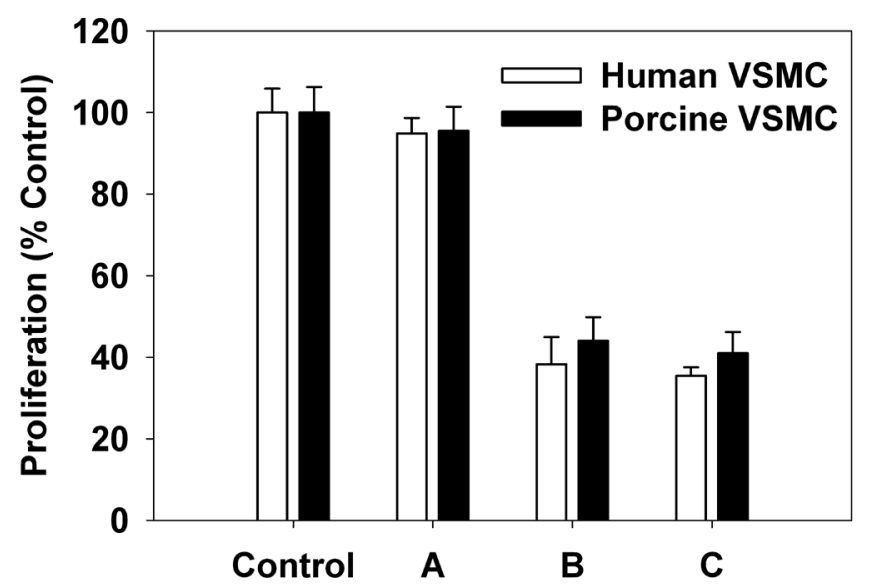

Figure 4: The impact of rapamycin on venous smooth muscle cells after it was released from ReGel in-vitro. (A) Rapamycin shows a dose-dependent inhibitory activity on the proliferation of human and porcine venous SMCs. (B) The inhibitory activity of rapamycin $(10 \mathrm{ng} / \mathrm{mL})$ released from ReGel compared the drug directly from the vial diluted to the same concentration. ReGel does not alter rapamycin's ability to inhibit SMCs. Samples of the plain culture medium alone were used as a control. Each data point represents the mean \pm SD of 6 experiments. The smooth muscle growth medium was supplemented with $10 \%$ fetal calf serum, $5 \mu \mathrm{g} / \mathrm{ml}$ insulin, $0.5 \mathrm{ng} / \mathrm{ml}$ human recombinant epidermal growth factor (EGF), $2 \mathrm{ng} / \mathrm{ml}$ human recombinant fibroblast growth factor (FGF), $50 \mu \mathrm{g} / \mathrm{ml}$ gentamicin and $50 \mathrm{ng} / \mathrm{ml}$ amphotericin-B. 


\section{Discussion}

We found that the release of rapamycin from ReGel was sustained for up to 50 days without an initial burst effect. This compares favorably to our previous results with dipyridamole.(Zhu et al., 2006) The difference in release profile might be attributed to the difference in hydrophobicity of the drug. Rapamycin is more hydrophobic than dipyridamole and is therefore likely to partition more into the hydrophobic core and less into the hydrophilic shell, assuming a domain structure of the polymer (Jeong, Bae, and Kim 2000). It is suggested that the drug release from the hydrophilic shell in the early time period results in the greater initial burst and a faster release of dipyridamole. The drug release from the hydrophobic core, which is dependent on polymer degradation, would give rapamycin a longer release period without the initial burst. Since neointimal formation in hemodialysis arteriovenous grafts usually occurs progressively over months, sustained drug release without an initial burst is likely to be more desirable to achieve the long-term antiproliferative effect.

Stenosis in the PTFE graft develops more often at the vein-graft anastomosis than the artery-graft anastomosis (Kanterman et al., 1995). Therefore, an understanding of the biology and responses of venous SMCs to antiproliferative agents is important to design optimal strategies to prevent graft stenosis. Despite the well-established effects of many antiproliferative agents in human and animal arterial SMCs, there is a paucity of data on their effects in venous SMCs. Our group has shown that of venous SMCs were more sensitive than arterial SMCs to the inhibitory effect of drug (Kim et al., 2004), but the reverse seemed to be true for the effect of gamma radiation (Kim et al., 2005). We therefore examined the cellular pharmacodynamics of rapamycin in human venous and arterial SMCs separately. Porcine venous and arterial SMCs were also examined to facilitate the understanding of any potential inter-species difference that might occur in drug response. As shown in Table 3, venous SMCs were more susceptible to the antiproliferative effect, and less susceptible to the toxicity, of rapamycin than arterial SMCs. In addition, venous SMCs exhibited the higher therapeutic index than arterial SMCs. These differences between venous and arterial SMCs were preserved between the species tested.

We also examined the antiproliferative effect and toxicity of rapamycin after it was released from ReGel. Released rapamycin inhibited the proliferation of human and porcine venous SMCs in a dose-dependent manner (Fig. 4A), with the potency similar to the stock drug (Fig. 4B). Released rapamycin at $0.1,10$ and $100 \mathrm{ng} / \mathrm{ml}$ did not induce cytotoxicity (data not shown).
ReGel is a triblock copolymer of polylactide-co-glycolide (PLGA)-polyethylene glycol (PEG)-PLGA, which is formulated as a $23 \%(\mathrm{w} / \mathrm{w})$ aqueous solution of polymers in PBS (Zentner et al., 2001). Its degradation products, monomeric or oligomeric lactic acid and glycolic acid may cause a decrease in local $\mathrm{pH}$ and affect SMC proliferation. An invitro experiment was therefore performed in which ReGel was incubated in culture medium and the medium was sampled daily for $\mathrm{pH}$ determination. The lowest $\mathrm{pH}$ (7.10 \pm $0.03 ; n=6$ ) was observed on day 1 . We further examined the effect of $\mathrm{pH}$ in the culture medium on SMC proliferation. It was found that a $\mathrm{pH}$ lower than 7.0 could significantly inhibit cell proliferation, compared to the $\mathrm{pH}$ of 7.4; whereas a $\mathrm{pH}$ between 7.0 and 7.4 did not affect cell proliferation. Here we demonstrated that ReGel neither affected SMC proliferation nor caused cytotoxicity. The presence of perivascular tissues in vivo in which ReGel is deposited should provide potent $\mathrm{pH}$ buffering. Thus, it is unlikely that the degradation products of ReGel would have significant impact on SMC proliferation during clinical administration.

In this study, we have demonstrated that (a) ReGel achieved a sustained release of rapamycin in-vitro, which should provide a continuous inhibitory effect in SMCs to prevent the graft stenosis in vivo; (b) the transport of rapamycin through the cell membrane followed a mechanism that is compatible with passive diffusion, and a substantial portion of rapamycin was retained in the cells; and (c) the incorporation of rapamycin in ReGel did not alter its potency in inhibiting SMC proliferation in a dose-dependent manner. The effectiveness of rapamycin delivered by ReGel in vivo would, however, further depend on the pharmacokinetics and pharmacodynamics of the drug in vascular tissues. Extension of the studies in cell culture into an animal model (such as a porcine PTFE graft model) will be a critical next step in the development of antiproliferative strategies.

$\operatorname{ReGel}^{\circledR}$ achieved a sustained release of rapamycin in-vitro. Rapamycin inhibited the proliferation of human and porcine venous and arterial SMCs in-vitro. Rapamycin released from $\mathrm{ReGel}$ retained its antiproliferative activity. ReGel can therefore be a potential sustained delivery system for rapamycin to inhibit SMC proliferation for the prevention of hemodialysis arteriovenous graft stenosis.

\section{Acknowledgements}

This work was supported by the National Heart, Lung and Blood Institute (RO1HL67646), the Merit Review Program of the Department of Veterans Affairs, the Dialysis Research Foundation and the National Kidney Foundation of Utah \& Idaho. ReGel ${ }^{\circledR}$ was kindly provided by MacroMed 
Inc. We thank Mr. Ilya Zhuplatov for assistance in cell culture studies. Drs. Donald Blumenthal, John K. Leypoldt, Li Li, Syed F. Mohammad and Christi Terry provided helpful comments.

\section{References}

1. Alexis F, Venkatraman SS, Rath SK, Boey F (2004) In vitro study of release mechanism of paclitaxel and rapamycin from drug-incorporated biodegradable stent matrices. J Control Release 98: 67-74. » CrossRef

» Pubmed " Google Scholar

2. Bierer BE, Mattila PS, Standaert RF, Herzenberg LA, Burakoff SJ, et al. (1990) Two distinct signal transmission pathways in T lymphocytes are inhibited by complexes formed between an immunophilin and either FK506 or rapamycin. Proc Natl Acad Sci USA 87: 9231-

5. " CrossRef " Pubmed " Google Scholar

3. Charlier A, Leclerc B, Couarraze G (2000) Release of mifepristone from biodegradable matrices: experimental and theoretical evaluations. Int J Pharm 200: 115-20.

"CrossRef " Pubmed " Google Scholar

4. Gallo R, Padurean A, Jayaraman T, Marx S, Roque M, et al. (1999) Inhibition of intimal thickening after balloon angioplasty in porcine coronary arteries by targeting regulators of the cell cycle. Circulation 99: 216470. " CrossRef " Pubmed " Google Scholar

5. Hille B (1984) Ionic Channels of Excitable Membranes. Sunderland: Sinauer Associates. "CrossRef » Pubmed " Google Scholar

6. Jeong B, Bae YH, Kim SW (2000) Drug release from biodegradable injectable thermosensitive hydrogel of PEG-PLGA-PEG triblock copolymers. J Control Release 63: 155-63. "CrossRef " Pubmed "Google Scholar

7. Johnson MS, McLennan G, Lalka SG, Whitfield RM, Dreesen RG (2001) The porcine hemodialysis access model. J Vasc Interv Radiol 12: 969-77. " CrossRef

» Pubmed " Google Scholar

8. Kanterman RY, Vesely TM, Pilgram TK, Guy BW, Windus DW, et al. (1995) Dialysis access grafts: anatomic location of venous stenosis and results of angioplasty. Radiology 195: 135-9. " CrossRef

» Pubmed " Google Scholar

9. Kelly BS, Heffelfinger SC, Whiting JF, Miller MA, Reaves A, et al. (2002) Aggressive venous neointimal hyperplasia in a pig model of arteriovenous graft stenosis. Kidney Int 62: 2272-80. " CrossRef " Pubmed " Google Scholar

J Bioequiv Availab
Research Article JBB/Vol.1 May-June 2009

10. Kim SJ, Masaki T, Leypoldt JK, Kamerath CD, Mohammad SF, et al. (2004) Arterial and venous smoothmuscle cells differ in their responses to antiproliferative drugs. J Lab Clin Med 144: 156-62. " CrossRef

» Pubmed " Google Scholar

11. Kim SJ, Masaki T, Rowley R, Leypoldt JK, Mohammad SF, et al. (2005) Different responses by cultured aortic and venous smooth muscle cells to gamma radiation. Kidney Int 68: 371-7. " CrossRef " Pubmed

» Google Scholar

12. Kuji T, Masaki T, Goteti K, Li L, Zhuplatov S, et al. (2006) Efficacy of local dipyridamole therapy in a porcine model of arteriovenous graft stenosis. Kidney Int 69: 2179-85. "CrossRef " Pubmed "Google Scholar

13. Lane P, Vichi P, Bain DL, Tritton TR (1987) Temperature dependence studies of adriamycin uptake and cytotoxicity. Cancer Res 47: 4038-42. "CrossRef

" Pubmed " Google Scholar

14. Marx SO, Jayaraman T, Go LO, Marks AR (1995) Rapamycin-FKBP inhibits cell cycle regulators of proliferation in vascular smooth muscle cells. Circ Res 76: 412-7. " CrossRef » Pubmed " Google Scholar

15. Masaki T, Rathi R, Zentner G, Leypoldt JK, Mohammad SF, et al. (2004) Inhibition of neointimal hyperplasia in vascular grafts by sustained perivascular delivery of paclitaxel. Kidney Int 66: 2061-9. " CrossRef

» Pubmed " Google Scholar

16. Poon M, Marx SO, Gallo R, Badimon JJ, Taubman MB, et al. (1996) Rapamycin inhibits vascular smooth muscle cell migration. J Clin Invest 98: 2277-83. " CrossRef

» Pubmed " Google Scholar

17. Rotmans JI, Velema E, Verhagen HJ, Blankensteijn JD, Kastelein JJ, et al. (2003) Rapid, arteriovenous graft failure due to intimal hyperplasia: a porcine, bilateral, carotid arteriovenous graft model. J Surg Res 113: 16171. "CrossRef " Pubmed " Google Scholar

18. Stein WD (1967) The Movement of Molecules across Cell Membranes. New York and London: Academic Press. " CrossRef » Pubmed " Google Scholar

19. Swedberg SH, Brown BG, Sigley R, Wight TN, Gordon $\mathrm{D}$, et al. (1989) Intimal fibromuscular hyperplasia at the venous anastomosis of PTFE grafts in hemodialysis patients. Clinical, immunocytochemical, light and electron microscopic assessment. Circulation 80: 1726-36.

»CrossRef » Pubmed " Google Scholar 
20. White PJ, Kumari R, Porter KE, London NJM, LL NG, et al. (2000) Antiproliferative effect of UTP on human arterial and venous smooth muscle cells. Am J Physiol Heart Circ Physiol 279: H2735-H42. " CrossRef

" Pubmed " Google Scholar

21. Yang Z, Oemar BS, Carrel T, Kipfer B, Julmy F, et al. (1998) Different proliferative properties of smooth muscle cells of human arterial and venous bypass vessels: role of PDGF receptors, mitogen-activated protein kinase, and cyclin-dependent kinase inhibitors. Circulation 97: 181-7. "CrossRef " Pubmed " Google Scholar
22.Zentner GM, Rathi R, Shih C, McRea JC, Seo MH, et al. (2001) Biodegradable block copolymers for delivery of proteins and water-insoluble drugs. J Control Release 72:203-15. " CrossRef " Pubmed " Google Scholar

23.Zhu W, Masaki T, Bae YH, Rathi R, Cheung AK, et al. (2006) Development of a sustained-release system for perivascular delivery of dipyridamole. J Biomed Mater Res 77B: 135-43. " CrossRef " Pubmed " Google Scholar 